\title{
Comparative Studies of the Methods of Determining Blood Alcohol with Reference to a Modification of Nicloux's Method.
}

\author{
$\mathrm{BY}$ \\ KUMAO YAMAKAMI. \\ (山上 熊 期) \\ (From the Department of Forensic Medicine, Tohoku \\ Imperial University, Sendai.)
}

In the practice of forensic medicine, there sometimes occurs a case, in which it is necessary to determine whether or not a given person found dead was under the influence of spirits at the moment of death.

In such cases the answer to the question can be found in the analysis of the blood.

Now, the quantity of alcohol contained in the distillate of blood not being very large in these cases, the usual physical methods of determining alcohol such as pycnometer, vaporimeter, ebullioscope etc. can not be employed, and only the chemical method is left for us to use.

Many chemical methods bave been hitherto devised for the purpose of determining small quantities of alcohol. According to their principles, these methods may be classed in four groups as described below.

Group I. In this group, the amount of alcohol is calculated from the quantity of acetic acid formed by oxidizing alcohol.

(a) Subbotin's method.1)

The acetic acid is titrated with $\mathrm{NaOH}$.

(b) Béchamp's method.2)

The amount of sodium acetate is determined.

Group II. In this group, the amount of alcohol is calculated from the quantity of jod compound.

(a) Sabbotin's method.1) Sabbotin measured the amount of iodoform formed in the Lieben's reaction.

(b) Striatar's method.s) In the method, the ethyl iodide formed by boiling alcohol with $\mathrm{HJ}$ is distilled and freed from $\mathrm{HJ}$ by means of red phosphorus and introduced into an alcoholic silver nitrate solution. The silver iodide thus produced is precipitated and weighed. 
Group III. The amount of alcohol is calculated from the quantity of aldehyde formed by oxidizing the alcohol.

Argenson's method.4) The aldehyde is introduced into a fuchsine solution decoloured by means of sulphurous acid, and the amount is colorimetrically estimated with the aid of a standard solution made of potassium permanganate.

Group IV. In this group, the reducing power of alcohol is determined by means of a standard solution of chromic acid.

(a) Bodländer's method.5) In this method, the given alcohol solution is added to a standard solution of chromic acid (1 grm. $\mathrm{CrO}^{3}$ in 300 c.c. $\mathrm{SO}_{4} \mathrm{H}_{2}$ ) until the yellow colour of the standard solution turus to deep green.

(b) Method of Benedict and Norris. ${ }^{6)}$

(c) Cotte's method.7)

(d) Nicloux's method.s'

Of these methods of deteming small quantities of alcohol, those of the first, second, and the third groups are not generally employed for the practical use, because the majority of them are much too complicated, and the result is not accurate enough to justify such complicated manipulations.

Three methods belonging to the fourth group have been generally employed for the purpose of determining small quantities of alcohol.

I have studied in the present work these three methods comparatively in order to determine which of them is best fitted for the purpose.

\section{Method of Benedict AND NorRis.}

This method depends on the oxidation of alcohol by an excess of chromic acid in a concentrated sulphuric acid solution and the determination of the excess of chromic acid by titration against ferrous ammonium sulphate solution, the end point being established by a standard solution of potassium permanganate. The reagents required for the determination are:

1. A solution of chromic acid in concentrated sulphuric acid $\left(2 \cdot 2063\right.$ grms. per 500 c.c. $\left.\mathrm{SO}_{4} \mathrm{H}_{2}\right)$.

2. A solution of ferrous ammonium sulphate ( 40 grms. per litre of $3 \% \mathrm{SO}_{4} \mathrm{H}_{2}$ solution).

3 . An approximately decinormal solution of potassium permanganate ( $3 \cdot 3$ grms. per litre).

4. A standard solution of alcohol in concentrated sulphuric acid (about 2 grms. of $5 \%$ alcohol made up to 50 c.c. with $\mathrm{SO}_{4} \mathrm{H}_{2}$ ).

5. Chemically pure concentrated sulphuric acid. 
The value of each solution in terms of the other is first determined in the following order.

1 c.c. $\mathrm{KMnO}_{4}$ solution $=\mathrm{X}$ c.c. $\mathrm{FeSO}_{4}\left(\mathrm{NH}_{4}\right)_{2} \mathrm{SO}_{4}$ solution.

1 c.c. $\mathrm{K}_{2} \mathrm{Cr}_{2} \mathrm{O}_{7}$ solution $=\mathrm{Y}$ c.c. $\mathrm{FeSO}_{4}\left(\mathrm{NH}_{4}\right)_{2} \mathrm{SO}_{4}$ solution.

1 c.c. standard alcohol solution $=$ c.c. $\mathrm{K}_{2} \mathrm{Cr}_{2} \mathrm{O}_{7}$ solution.

From the above determinations, the amount of alcohol equivalent to 1 c.c. of the ferrous ammonium sulphate solution is calculated, and this factor is used in calculating the alcohol in the other solutions.

For the determination of alcohol in a given solution, the strength of the solution is first determined roughly by means of a pycnometer, and if the solution contains more than $1 \%$ alcohol, such a quantity as will cuntain about $0.1 \mathrm{grm}$. of absolute alcohol is weighed accurately into a 50 c.c. graduated flask and 10 c.c. concentrated sulphuric acid is added keeping the flask cool by immersion in cold water. The solution is then made up to the 50 c.c. mark with concentrated sulphuric acid.

5 c.c. of the mixture is then drawn off into a small flask, 20 c.c. chromic acid solution are added and the contents of the flask are heated to $98^{\circ} \mathrm{C}$. and kept at this temperature for 5 minutes. The solution is then cooled and poured into 200 c.c. of distilled water and ferrous ammonium sulphate solution is adied from a burette until the excess of chromic acid is completely reduced. The excess of ferrous ammonium sulphate is then determined with the standard potassium permanganate solution. The calculation is made in the following way.

mg. alc. $=($ alc. equivalent of fe. am. sul. $) \times$

$$
\left(\frac{\text { P. bichr. used }- \text { fe. am. sul. added }+ \text { P. permag. added }}{\text { c.c. alc. solution used }}\right)
$$

If the given alcohol solution contains less than $1 \%$ alcohol, 0.5 c.c. is drawn into a 100 c.c. flask, and about 5 c.c. of concentrated sulphuric acid and 10 c.c. of the chromic acid solution are added, and the determination is carried out as above.

(For the detailed precautions, reference to the original paper is recommended).

I have prepared alcohol solutions of various strengths (volume percent) and tested the accuracy of this method.

The results are given in the following table:-

TabLe I.

$\mathrm{FeSO}_{4}\left(\mathrm{NH}_{4}\right)_{2} \mathrm{SO}_{4} 10$ c.c. : $\mathrm{KMnO}_{4} 9.62$ c.c.

$\mathrm{K}_{2} \mathrm{Cr}_{2} \mathrm{O}_{7} 10$ c.c. : $\mathrm{FeSO}_{4}\left(\mathrm{NH}_{4}\right)_{2} \mathrm{SO}_{4} 10$ c.c. : $\mathrm{KMnO}_{4} 1.25$ c.c.

1 c.c. standard alcohol $=0.00213$ grm. alcohol.

Standard alcohol 2 c.c. : $\mathrm{K}_{2} \mathrm{Cr}_{2} \mathrm{O}_{7} 10$ c.c. : $\mathrm{FeSO}_{4}\left(\mathrm{NH}_{4}\right)_{2} \mathrm{SO}_{4} 5$ c.c. : $\mathrm{KMnO}_{4} 0 \cdot 32$ c.c.

1 c.c. $\mathrm{FeSO}_{4}\left(\mathrm{NH}_{4}\right)_{2} \mathrm{SO}_{4}=6.989 \mathrm{mgrm}$. alcohol.

\begin{tabular}{|c|c|c|}
\hline $\begin{array}{l}\text { Volume \% of the alcohol } \\
\text { solutions employed }\end{array}$ & Weight $\%$ found & $\begin{array}{l}\text { Volume } \% \text { calculated from } \\
\text { the weight } \% \text { found }\end{array}$ \\
\hline $\begin{array}{l}0.200 \% \\
0.150 " \\
0.080 " \\
0.050 " \\
0.020 " \\
0.010 " \\
0.005 "\end{array}$ & $\begin{array}{l}0.1982 \% \\
0.1413 " \\
0.0652 ", \\
0.0414 " \\
0.0235 ", \\
0.0170 " \\
0.0111 ",\end{array}$ & $\begin{array}{l}0.218 \% \\
0.177 " \\
0.081 " \\
0.052 " \\
0.029 " \\
0.021 " \\
0.014 "\end{array}$ \\
\hline
\end{tabular}


(Alcohol solutions of volume percentage were employed for the sake of convenience in comparing the accuracy of this method with that of the others.)

The superiority of this method lies in the sharpness of the end point. Only a single drop of the potassium permanganate solution is sufficient to cause a sudden colour change of the ferrous ammonium sulphate solution from blue to purple at the end point.

Such a sharpness of the end point as this can be met with in no other method.

But this method has many defects which cancel this superiority.

First of all, the reagents, especially the chromic acid and the ferrous ammonium sulphate solution quickly change their strength with the lapse of time. The chromic acid solution seems to absorb readily the vapour of alcohol and water. Consequently, the value of each solution in terms of the other must be titrated almost daily, especially when the air of the laboratory contains alcohol vapour.

Table II shows how quickly the ferrous ammonium sulphate and chromic acid solution change their equivalent. ('The solutions were not stored unused but were continuously employed for the determination of alcohol.

TABLE II.

\begin{tabular}{c|c|c}
\hline $\begin{array}{c}\text { Date of } \\
\text { determination }\end{array}$ & $\frac{\mathrm{KMnO}_{4}}{\mathrm{FeSO}_{4}\left(\mathrm{NH}_{4}\right)_{2} \mathrm{SO}_{4}}$ & $\frac{\mathrm{FeSO}_{4}\left(\mathrm{NH}_{4}\right)_{2} \mathrm{SO}_{4}}{\mathrm{~K}_{2} \mathrm{Cr}_{2} \mathrm{O}_{7}}$ \\
\hline $12 . \mathrm{X}$. & 0.965 & 0.915 \\
$15 . "$ & 0.960 & 0.905 \\
$18 . "$ & 0.952 & 0.890 \\
$20 . "$ & 0.950 & 0.890 \\
$25 . "$ & 0.930 & 0.885 \\
$30 . "$ & 0.915 & 0.875 \\
2. XI. & 0.910 & 0.875
\end{tabular}

It is quite troublesome to determine the values of the solutions daily.

Another inconvenience of this method is that alcohol solutions weaker than $0.01 \%$ can not be determined by the aid of this method, because 0.5 c.c. of $0.01 \%$ alcohol solution corresponds to about 0.1 c.c. potassium lermanganate solution.

I have tried in vain to modify this method in such a way that this inconvenience might be removed. The increase of the amount of alcohol solution, the dilution of the rogent solutions etc. could not 
produce any appreciable improvement. This method is too complicated and even after having acquired a good deal of practice, technical errors of a considerable amount can not be avoided.

For these reasons, this method can not be recommended for the determination of alcohol in very dilute solutions such as the distillate of physiological blood which generally contains less than $0.003 \%$ of alcohol.

\section{Method of Cotte.}

In this method, the end point is established, not by a permanganate solution but by a standard solution of ferrous ammonium sulphate with the aid of "Tüpfelprobe."

The reagents required for the determination are:

1. $\mathrm{M} / 20 \mathrm{~K}_{2} \mathrm{Cr}_{2} \mathrm{O}_{7}$ in $20 \% \mathrm{SO}_{4} \mathrm{H}_{2}$.

2. $\mathrm{M} / 20 \mathrm{FeSO}_{4}\left(\mathrm{NH}_{4}\right)_{2} \mathrm{SO}_{4}$ in $5 \% \mathrm{SO}_{4} \mathrm{H}_{2}$.

3. $10 \% \mathrm{~K}_{6} \mathrm{Fe}_{2}(\mathrm{CH})_{12}$.

The ralue of the potassium bichromate solution in terms of the ferrous ammonium sulphate solution is first determined. Toward the end point of the reaction, the yellowish red colour of the chromic acid solution changes gradually yellowish green $\rightarrow$ green $\rightarrow$ bluish green $\rightarrow$ greenish blue $\rightarrow$ blue. When this point has been reached, the ferrous ammonium sulphate solution is added carefully drop by drop trying the "Tüpfelprobe" at the addition of each drop.

The "Tüpfelprobe" (stain test) is carried out in the following way. One drop of the potassium ferricyanide solution is put on a very clean filter paper, and then a drop of the liquid to be tested is brought close to the former drop. Both drops quickly spread on the paper and come in contact with each other. If the liquid to be tested contains any trace of ferrous ions, the yellow stain of the ferricyanide solution will turn blue, due to the formation of Turnbull's blue, in the contact zone with the almost colourless stain of the other drop. (It seems to be generally believed that this blue colour is due to the production of Prussian blue (Pringsheim). But doubtlessly this can not be so.)

When the value of the bichromate solution in terms of the ferrous ammonium sulphate solution has been thus determined, the value of the former solution in terms of alcohol is estimated in the following way.

An accurately measured amount of $1 \%$ (volume $\%$ ) alcohol solution is taken in an Erlenmeyer flask, and an excess of the bichromate solution is added, and the flask is tightly stoppered, and heated in a water bath for $1-1 \frac{1}{2}$ hours at $80-90^{\circ} \mathrm{C}$. The flask is then cooled to the room temperature, and the excess of potassium bichromate is titrated with the ferrous ammonium sulphate solution, employing the stain test with potassium ferricyanide solution for establishing the end point.

The alcohol equivalent of the bichromate solution can then be calculated by subtracting the bichromate equivalent of the ferrous ammonium sulphate solution from the amount of the bichromate solution employed.

1 c.c. of $1 \%$ alcohol solution will generally reduce $225-2.30$ c.c. of the bichromate 
solution. This value is employed in the calculation of alcohol in the other solutions.

For the determination of alcohol in a given solution, the bichromate equivalent of alcohol in a measured quantity of the solution is first determined by the same procedure as in the case of the determination of the value of bichromate solution in terms of $1 \%$ alcohol. The unknown percentage of the given alcohol solution can then be obtained by dividing it by the bichromate equivalent of $1 \%$ alcohol.

If the given alcohol solution contains a very small quantity of alcohol, as in the case of the distillate of physiological blood, M/40 solutions of bichromate as well as of ammonium sulphate are employed instead of the $\mathrm{M} / 20$ solutions.

'The alcohol solutions of various strengths employed in the preceding experiments were determined by this method.

The results are given in the following table.

TABLE III.

1 c.c. $M / 40$ bichromate solution $=6 \cdot 3$ c.c. $M / 40$ ammonium sulphate solution.

1 c.c. $1 \%$ alcohol solution $=4445$ c.c. $\mathrm{M} / 40$ bichromate solution.

\begin{tabular}{|c|c|c|c|c|}
\hline $\begin{array}{c}\% \text { of the alcohol } \\
\text { solutions em- } \\
\text { ployed } \\
\text { (volume } \% \text { ) }\end{array}$ & $\begin{array}{l}\text { Amount of the } \\
\text { alcohol solu- } \\
\text { tions employed }\end{array}$ & $\begin{array}{l}\text { Amount of the } \\
\text { bichromate solu- } \\
\text { tions added }\end{array}$ & $\begin{array}{l}\text { Amount of the } \\
\text { sulphate solu- } \\
\text { tion used }\end{array}$ & $\begin{array}{c}\% \text { of alcohal } \\
\text { found } \\
\text { (volume \%) }\end{array}$ \\
\hline 0.2000 & 5 c.c. & 5 c.c. & 5 c.c. & 0.1900 \\
\hline 0.1500 & 5, & $5 n$ & $102 "$ & 0.1520 \\
\hline 0.0800 & $5 "$ & 5, & $19 \cdot 4 "$ & 0.0853 \\
\hline 0.0500 & $5 "$ & $5 \%$ & $24 \cdot 1 "$ & 0.0517 \\
\hline 0.0200 & $10 "$ & 5, & $24.0 "$ & 0.0260 \\
\hline 0.0100 & $20 "$ & $5 \%$ & $25.4 "$ & 0.0109 \\
\hline 0.0050 & 20 & $5 \%$ & $28 \cdot 6$ & 0.0051 \\
\hline 0.0020 & $20 "$ & $5 \%$ & $30.2 "$ & 0.0023 \\
\hline 0.0010 & 20, & $5 n$ & $31 \cdot 1$, & 0.0009 \\
\hline 0.0005 & $20 "$ & $5 \%$ & $31 \cdot 25$, & 0.0006 \\
\hline
\end{tabular}

Whereas it is necessary for the method of Benedict and Norris to determine three equivalents of the reagent solutions that is,

$$
\begin{aligned}
& \mathrm{K}_{2} \mathrm{MnO}_{4}: \mathrm{FeSO}_{4}\left(\mathrm{NH}_{4}\right)_{2} \mathrm{SO}_{4} \\
& \mathrm{~K}_{2} \mathrm{Cr}_{2} \mathrm{O}_{7}: \mathrm{FeSO}_{4}\left(\mathrm{NH}_{4}\right)_{2} \mathrm{SO}_{4} \\
& \text { Standard alcohol solution: } \mathrm{K}_{2} \mathrm{Cr}_{2} \mathrm{O}_{7} \text {, }
\end{aligned}
$$

as already mentioned in the preceding section, only two equivalents, that is,

$$
\mathrm{K}_{2} \mathrm{Cr}_{2} \mathrm{O}_{7}: \mathrm{FeSO}_{4}\left(\mathrm{NH}_{4}\right)_{2} \mathrm{SO}_{4}
$$

Standard alcohol solution : $\mathrm{K}_{2} \mathrm{Cr}_{2} \mathrm{O}_{7}$, 
The defect of Cotte's method lies in the inconvenience in the determination of the end point.

The stain test with potassium ferricyanide solution cannot establish the point with very great precision where potasium bichromate has been just completely reduced and a very small trace of ferrous ions has begun to appear in the liquid.

'The colour of Turnbull's blue in the contract zone of two drops does not appear suddenly and clearly at a definite point of the reaction, but its appearance is rather gradual.

The intensity as well as the readiness of the appearance of the blue colour are augmented toward the end point by each addition of ferrous ammonium sulphate solution until a sudden and clear colour change in the contact zone of the drops takes place almost immediately.

The end point is, therefore, not very accurate and certain. Moreover it is not convenient to try the stain test at each addition of ferrous ammonium sulphate solution.

Notwithstanding these defects, however, the results obtained with Cotte's method are very accurate as shown in table III, if practice has been acquired. 'The simplicity of this method diminishes the technical errors which often occur in the case of Benedict-Norris method, and compensates for the defects above described.

The superiority of this method lies especially in its applicability to very dilute alcohol solutions. As will be noticed in the given table, alcohol can be determined even in a solution of $0.0005 \%$ with fair accuracy.

The only thing which must be borne in mind, when very dilnte alcohol solutions are to be determined by the aid of this method, and of which I could not find any description in the literature of the subject as far as I have been able to refer to it, is the proportion between the volume of potassium bichromate solution and that of the alcohol solution to be determined.

A mere excess of the bichromate solution to oxidize the given quantity of alcohol is not sufficient, but a quantity of bichromate solution more than $\frac{1}{4}$ of the volume of alcohol solution must be added.

This is probably due to the fact that the power of bichromate solution oxidizing alcohol depends partly on the acidity or the concentration of $\mathrm{SO}_{4} \mathrm{H}_{2}$ in the liquid.

This fact is illustrated in the next table. 
Table IV.

\begin{tabular}{|c|c|c|c|c|c|}
\hline $\begin{array}{l}\% \text { of alcohol } \\
\text { solutions } \\
\text { employed }\end{array}$ & $\begin{array}{l}\text { Amount of } \\
\text { alcohol } \\
\text { solutions } \\
\text { employed }\end{array}$ & $\begin{array}{c}\text { Amount of } \\
\text { distilled water } \\
\text { added }\end{array}$ & $\begin{array}{l}\text { Amount of } \\
\text { bichromate } \\
\text { solution } \\
\text { added }\end{array}$ & $\begin{array}{l}\text { Amount of } \\
\text { sulphate solu- } \\
\text { tion used }\end{array}$ & $\begin{array}{l}\% \text { of alcohol } \\
\text { found }\end{array}$ \\
\hline 0.01 & 20 c.c. & - & 5 c.c. & 25.4 c.c. & 0.0109 \\
\hline 001 & $20 "$ & 20 c.c. & $5 "$ & $27 \cdot 2$ & 0.0076 \\
\hline 0.01 & $20 "$ & 60, & $5 \%$ & $30 \cdot 1 "$ & 0.0025 \\
\hline 0.005 & $20 "$ & - & & $28 \cdot 6 "$ & 0.0051 \\
\hline 0.005 & 30, & - & & 29.5, & 0.0020 \\
\hline 0.005 & $30 "$ & - & $2 \cdot 5$, & $15.5 "$ & 0.00013 \\
\hline
\end{tabular}

As will be seen in the table, the amount of ferrous ammonium sulphate solution which is to be added in order to reduce the potassium bichromate left unattacked by alcohol increases with the increase of the volume of the alcohol solution employed, even when the amount of alcohol and bichromate remains always the same, provided that the proportion between the volume of alcohol- and bichromate solutions is greater than $4: 1$.

(N.B. The purity of the distilled water employed in the experiment was, as a matter of course, examined previous to the experiment.)

\section{METhod of NicLoux.}

This is the simplest of all the methods hitherto devised for the purpose of determining small quantities of alcohol.

In this method alcohol is titrated directly with a standard solution of potassium bichromate, utilizing the colour change which occurs at the point where the oxidation of alcohol by potassium bichromate has been completed and a small trace of bichromate has begun to appear in the liquid, for establishing the end point.

Only one reagent, that is a standard solution of potassium bichromate which contains 19 grms. of pure bichromate crystal per litre, is all that is to be prepared for the cletermination.

For very dilute solutions, it is recommended to dilute the standard solution to $\frac{1}{2}$ or $\frac{1}{4}$.

The determination is carried out in the following way:-

5 c.c. of the given alcohol solution is put in a colourless test tube and $0 \cdot 1$ c.c. of the standard solution (a quantity which is generally too small to oxidize the given quantity of alcohol completely) as well as 5 c.c. pure concentrated sulphuric acid. The mixture becomes very hot and a colour change due to the decoloration of bichromate takes place.

From a graduated burette, the standard bichromate solution is then added drop by 
drop, keeping the temperature of the liquid at about $100^{\circ} \mathrm{C}$., and shaking the test tube all the while until the pure blue colour of the liquid turns to greenish blue.

The number of c.c. of the standard bichromate solution used indicates directly the permillage of alcohol in the given solution.

If the given alcohol solution contains more than $0.2 \%$ alcohol, the solution must be diluted, because the optimum of the distinct colour change at the end point lies between $0.15-0.05 \%$.

And if the alcohol solution is weaker than $0.05 \%$, it is preferable to dilute the bichromate solution and redouble the quantity of alcohol solution as well as that of $\mathrm{SO}_{4} \mathrm{H}_{2}$.

I have determined by the aid of this method, the alcohol solutions which were employed for the studies of the reliability of the other two methods.

Table V shows the results obtained.

TABLE V.

\begin{tabular}{|c|c|c|c|c|}
\hline $\begin{array}{c}\% \text { of the alcahol } \\
\text { solutions } \\
\text { employed }\end{array}$ & $\begin{array}{l}\text { Dilution of the } \\
\text { bichromate } \\
\text { solution }\end{array}$ & $\begin{array}{l}\text { Amount of al- } \\
\text { cohol solutions } \\
\text { employed }\end{array}$ & $\begin{array}{l}\text { Amount of the } \\
\text { bichromate solu- } \\
\text { tion added }\end{array}$ & $\begin{array}{l}\% \text { of alcohol } \\
\text { found }\end{array}$ \\
\hline $0 \cdot 2000$ & $1 / 1$ & 5 c.c. & $1.85 \mathrm{c.c}$ & $0 \cdot 1850$ \\
\hline 0.1500 & $1 / 1$ & $5 \%$ & $1.40 "$ & $0^{\cdot} 1400$ \\
\hline 0.0800 & $1 / 1$ & $5 \%$ & $0.73 "$ & 0.0730 \\
\hline 0.0500 & $1 / 1$ & 5, & $0.50 "$ & 0.0500 \\
\hline 0.0200 & $1 / 2$ & $5 "$ & 0.35 & 0.0175 \\
\hline 0.0100 & $1 / 2$ & $5 \%$ & 0.20 & 0.0100 \\
\hline 0.0050 & $1 / 2$ & 10, & $0.20 "$ & 0.0050 \\
\hline 0.0020 & $1 / 2$ & $10 "$ & $0 \cdot 10 "$ & 0.0025 \\
\hline 0.0010 & $1 / 4$ & 10, & 0.20 & 0.0010 \\
\hline 0.0005 & $1 / 4$ & $10 "$ & $0 \cdot 10$ & 0.0005 \\
\hline
\end{tabular}

A great deal of discussion has been hitherto taken place for and against the reliability of this method.

La nds berg ${ }^{10}$ raised the objection that the amount of bichromate solution which is to be added in order to effect the complete oxidation of alcohol varies with the quantity of sulphuric acid added, and furthermore that the colour change does not take place always at a definite point, of instance, in the determination of $0.1 \%$ alcohol solution, he had to add the bichromate solution 0.83 c.c. when 3 c.c. sulphuric acid was added, and 0.91 c.c. when 5 c.c. $\mathrm{SO}_{4} \mathrm{H}_{2}$ was added, and the colour change in the former case occurred at $0 \cdot 8,0 \cdot 8,0 \cdot 9,0 \cdot 8,0 \cdot 9,0.7$ c.c. etc.

According to him, Béhal and François also obtained similar results, and they employed, therefore, a solution containing 16.97 grms. of $\mathrm{K}_{2} \mathrm{Cr}_{2} \mathrm{O}_{7}$ per litre, of which 1 c.c. corresponded to 0.005 c.c. alcohol, instead of Nicloux's solution. 
Pringsheim cites the objection of Pezzi-Escot who denies the reliability of Nicloux's method.

I can confirm all the points of objection which Lands berg raised against this method.

Notwithstanding all these objections, this method can be, and has been hitherto employed practically with moderate convenience and with fairly accurate results for the determination of small quantities of alcohol.

As will be seen in the accompanying table, I have obtained far better results with this method than those obtained with Benedict's method. The simplicity of this method compensates for all the defects above described.

W. Schweisheimer writes in his communication on "Der Alkoholgehalt des Blutes unter verschiedenen Bedingungen" 11), that "selbst bei Untersuchungen von destilliertem Wasser sind stets 1-2 Tropfen der Kaliumbichromatlösung II zur Erziehung einer leichten Gelbfärbung nötig, so dass das Resultat 0 nicht erzielt werden kann."

But according to my own experience, even 1 drop of $\frac{1}{4}$ standard bichromate solution can cause a distinct yellow colour, when distilled water is tested and it seems very probable that Schweisheimer errployed in his experiment sulphuric acid which contained a trace of reducing substance.

Concentrated sulphuric acid very readily absorbs the vapour of alcohol, and consequently the sulphuric acid must be frequently tested for its purity, especially when the air of the laboratory is contaminated with alcohol vapour, as is often the case when the experiment deals with the determination of alcohol.

The colour of the liquid can be reliably examined by placing the container of the liquid on a clean white paper which is folded at right angles so that the folded part of the paper makes a white background for the liquid.

As denoted in Table $\mathrm{V}$, alcohol in a solution even weaker than $0.001 \%$ can be determined approximately by the aid of this method.

\section{A MOdification OF NiCloux's METHOD.}

The main inconvenience of Nicloux's method lies in the uncertainty of its end point, as Landsberg, Béhal and François have 
already pointed out. In my own experiment, I have obtained the following results.

5 c.c. of $0.2 \%$ alcohol +5 c.c. $\mathrm{SO}_{4} \mathrm{H}_{2}+$ bichromate solution $1 \cdot 75$, $1 \cdot 9,1.92,1 \cdot 8,1 \cdot 90 \mathrm{c} \cdot \mathrm{c}$.

Such variability of the end point as this is doubtlessly caused, as Landsberg suggests, by the evaporation of aldehyde and unoxidized alcohol during the titration.

The same cause is probably also responsible for the low values which are obtained in the determination of alcohol solutions of strong concentration (Table V).

I have therefore tried to modify the technique of this method in order to avoid the evaporation of alcohol and aldehyde, by adopting the technique of Cotte's method, and obtained the expected results.

The determination was carried out in the following manner.

The amount of the bichromate solution required for the complete oxidization of the given quantity of alcohol was first determined in the usual way of titration.

Then to each of three small flasks of colourless glass, 5 c.c. of the given alcohol solution and the amount of bichromate solution found in the preceding titration were put in, and then $1,2,3$ drops $(0.05,0 \cdot 1,0.15$ c.c.) of bichromate solution were added respectively to each of the flasks. 5 c.c. of $\mathrm{SO}_{4} \mathrm{H}_{2}$ were slowly let in along the wall of the flask. Sulphuric acid when let in this way goes directly to the bottom of the flask, without mixing with the liquid, and consequently no liberation of heat is effected.

The flasks were then tightly stoppered and shaken and kept at $70-50^{\circ} \mathrm{C}$. in a water

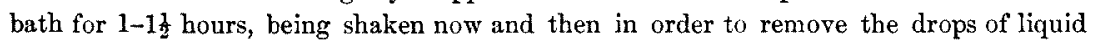
condensated on the wall. The first flask which assumed a green tone was taken as the end point. The end point when determined in this way is very definite, and always adranced $0.05-0.15$ c.c. further than that determined in the usual way.

The results obtained with the modified technique are presented in the last table.

TAble VI.

\begin{tabular}{|c|c|c|c|}
\hline $\begin{array}{l}\% \text { of the alcohol } \\
\text { solutions employed }\end{array}$ & $\begin{array}{l}\text { Dilution of the } \\
\text { bichromate } \\
\text { solution }\end{array}$ & $\begin{array}{c}\text { Amount of the bichromate } \\
\text { solution used } \\
\text { (c.c.) }\end{array}$ & $\begin{array}{l}\% \text { of alcohol } \\
\text { found }\end{array}$ \\
\hline 0.200 & $1 / 1$ & $1.95 . \quad 1.95$ & 0.195 \\
\hline 0.151 & $1 / 1$ & $1 \cdot 5 . \quad 1.45$ & 0.148 \\
\hline 0.080 & $1 / 1$ & $\begin{array}{ll}0.8, & 0.8\end{array}$ & 0.080 \\
\hline 0.050 & $1 / 1$ & $0 . \overline{0} . \quad 0.6$ & 0.050 \\
\hline
\end{tabular}




\section{SUMmaRY.}

1. The method of Benedict and Norris is not fitted for determining alcohol in a solution weaker than $0.01 \%$. Though it has the advantage that its end point can be established very conveniently and definitely, the results obtained by this method are not in any degree better than those obtained by the aid of Nicloux's or Cotte's method, because its technique is too complicated and the reagents change their value quickly.

2. Cotte's method can be reliably employed even to very dilute solutions of alcohol, provided only that the proportion between the volume of alcohol solution and that of the bichromate solution is properly chosen $(4: 1)$.

3. Nicloux's methor, modified in its technique, gives quite satisfactory results.

\section{Liverature.}

(1) Subbotin, Zeitschr. f. Biol. 1871, 7, 361.

(2) Béchamp, Cited in Pringshe im, Biochem. Zeitschr., 1908, 12, 151.

(3) Striata r, Zeitschr. f. physiol. Chem., 1906, 50, 210.

(4) Argenson, Cited in Pringshe im, Biochen. Ztschr., 1908, 12, 154.

(5) Bodlünder, Pflüger's Arch., 1883, 32, 398.

(6) Benedict and Norris, Journ. of the Am. Chem. Soc., 1898, 20, 293.

(7) Cotte, Cited in Pringsheim, Biochem. Ztschr. 1908, 12, 153.

(8) Nicloux, Cited in Schweisheimer, Deutsch. Arch. f. klin. Med., 1913, 109, 272.

(9) Landsberg, Zeitsehr. f. physiol. Chem., 1904, 41, 505.

(10) Schweisheimer, Deutsch. Arch.f. klin. Med., 1913, 109, 271. 